\title{
QUEEN'S
UNIVERSITY
BELFAST
}

\section{Constitutive modeling, microstructure evolution, and processing map for a nitride-strengthened heat-resistant steel}

Zhang, W-F., Sha, W., Yan, W., Wang, W., Shan, Y., \& Yang, K. (2014). Constitutive modeling, microstructure evolution, and processing map for a nitride-strengthened heat-resistant steel. Journal of Materials Engineering and Performance, 23(8), 3042-3050. https://doi.org/10.1007/s11665-014-1026-4

Published in:

Journal of Materials Engineering and Performance

Document Version:

Peer reviewed version

Queen's University Belfast - Research Portal:

Link to publication record in Queen's University Belfast Research Portal

Publisher rights

This is the author's accepted manuscript of this article. The final publication is available at Springer via http://dx.doi.org/10.1007/s11665-0141026-4

\section{General rights}

Copyright for the publications made accessible via the Queen's University Belfast Research Portal is retained by the author(s) and / or other copyright owners and it is a condition of accessing these publications that users recognise and abide by the legal requirements associated with these rights.

Take down policy

The Research Portal is Queen's institutional repository that provides access to Queen's research output. Every effort has been made to ensure that content in the Research Portal does not infringe any person's rights, or applicable UK laws. If you discover content in the Research Portal that you believe breaches copyright or violates any law, please contact openaccess@qub.ac.uk. 


\title{
Constitutive modeling, microstructure evolution and processing map for a nitride strengthened heat resistant steel
}

\author{
Wen-Feng ZHANG ${ }^{1,2,3}$, Wei SHA ${ }^{4}$, Wei YAN ${ }^{2}$, Wei WANG ${ }^{2}$, Yi-Yin SHAN $^{2}$, Ke \\ $\mathrm{YANG}^{2, *}$ \\ ${ }^{1}$ University of Science and Technology of China, Hefei 230026, China \\ ${ }^{2}$ Institute of Metal Research, Chinese Academy of Sciences, Shenyang 110016, China \\ ${ }^{3}$ Graduate School of Chinese Academy of Sciences, Beijing 100049, China \\ ${ }^{4}$ School of Planning, Architecture \& Civil Engineering, Queen's University Belfast, Belfast \\ BT9 5AG, UK \\ *Corresponding author. Tel./fax: +86 24 23971628; E-mail address: kyang@imr.ac.cn (Ke Yang)
}

\begin{abstract}
A constitutive equation was established to describe the deformation behavior of a nitride strengthened (NS) steel through isothermal compression simulation test. All the parameters in the constitutive equation including the constant and the activation energy were precisely calculated for the NS steel. The result also showed that from the stress-strain curves, there existed two different linear relationships between critical stress and critical strain in the NS steel due to the augmentation of auxiliary softening effect of the dynamic strain-induced transformation (DSIT). In the calculation of processing maps, with the change of Zener-Hollomon value, three domains of
\end{abstract}


different levels of workability were found, namely excellent workability region with equiaxed-grain microstructure, good workability region with 'stripe' microstructure, and the poor workability region with martensitic-ferritic blend microstructure. With the increase of strain, the poor workability region firstly expanded, then shrank to barely existing, but appeared again at the strain of 0.6 .

Keywords: steel; martensite; thermomechanical processing; mechanical characterization; light microscopy; recrystallization

\section{Introduction}

Heat resistant steels being used as pressure vessels, boilers and piping systems in power generating plants are extruded into pipes, tubes and fittings at high temperature $^{[1]}$. Therefore, it is of essential importance to study the deformation characteristics and the microstructure evolution of these steels during hot deformation. The nitride strengthened (NS) martensitic heat resistant steels are precipitation strengthened mainly by particles of MX type ${ }^{[2]}$, which are assumed to have a low coarsening rate, a quarter of that of $\mathrm{M}_{23} \mathrm{C}_{6}$ precipitates ${ }^{[3]}$. Thus, the NS steels with high hot microstructure stability are assumed to be the most competitive candidates for the application at $650{ }^{\circ} \mathrm{C}$ thanks to their high heat conductivity, nice thermal fatigue resistance and high stress corrosion resistance ${ }^{[4]}$.

Thermomechanical processing (TMP) has become a crucial tool to improve the structure and enhance the mechanical properties of steels. During a TMP process, recrystallization plays the main role in the microstructure evolution ${ }^{[5]}$, which mainly determines the deformation characteristics of the steels. Besides the recrystallization 
including dynamic recrystallization (DRX), metadynamic recrystallization (MDRX), and static recrystallization (SRX), other softening mechanisms may also have strong effects on the deformation behavior, such as dynamic recovery (DRV), static recovery (SRV), and dynamic strain induced transformation (DSIT). Each of the softening mechanisms has to satisfy its own prerequisite in order to take place. For example, DRX, which is the most important way to refine the grains, only occurs when a critical strain is reached, and at the same time, the minimum rate of energy dissipating is received ${ }^{[6]}$. Which softening mechanisms operate in the microstructure evolution depends on the chemical composition, prior machining procedures and the deformation parameters. The DRV reducing the stored energy greatly and making DRX hard to happen takes place at all levels of strain beyond $0.1^{[7]}$, while the MDRX usually happens between rolling stages and only changes the growth of grains nucleated during DRX. It is also believed that MDRX would also take place under the deformation condition of a small strain rate ${ }^{[8]}$. Finally, DSIT happens when two preconditions, the critical strain for DSIT and the temperature being above $\mathrm{Ar}_{3}$, are met simultaneously. According to previous work, the DSIT occurred before DRX in the case of NS steel ${ }^{[9]}$ and effected the evolution of microstructure greatly.

This paper aims to establish the constitutive equations for an NS martensitic steel and to establish optimum processing parameters according to the processing map of energy dissipation efficiency. 


\section{Experimental}

The chemical composition of the NS steel is given in Table 1 . The lower $\mathrm{C}$ and $\mathrm{N}$ contents comparing to commercial steel should be noted. The steel was melted in a vacuum induction-melting furnace and then forged into slabs at $900-1150{ }^{\circ} \mathrm{C}$ with a transversal surface of $60 \times 90 \mathrm{~mm}^{2}$. Bars for the compression test, cut from the slab perpendicular to the forging direction, were machined into samples of $8 \mathrm{~mm}$ in diameter and $12 \mathrm{~mm}$ in gauge length.

All the samples were homogenized in vacuum at $1200{ }^{\circ} \mathrm{C}$ for $5 \mathrm{~min}$, and then cooled down to the deformation temperature of $900-1200{ }^{\circ} \mathrm{C}$ at the rate of $10{ }^{\circ} \mathrm{C} / \mathrm{s}$. After isothermal stabilizing for $1 \mathrm{~min}$ at the deformation temperature, the samples were deformed up to $60 \%$ in a strain rate range of $10^{-3}-1 \mathrm{~s}^{-1}$. The samples were quenched to room temperature as soon as the compression was finished. The procedure is illustrated in Fig. $1^{[9]}$.

Table 1 Chemical composition of the experimental steel, wt $\%$

\begin{tabular}{llllllll}
\hline $\mathrm{C}$ & $\mathrm{Si}$ & $\mathrm{Mn}$ & $\mathrm{Cr}$ & $\mathrm{W}$ & $\mathrm{V}$ & $\mathrm{Nb}$ & $\mathrm{N}$ \\
\hline 0.021 & 0.09 & 1.25 & 9.37 & 1.42 & 0.15 & 0.06 & 0.037 \\
\hline
\end{tabular}




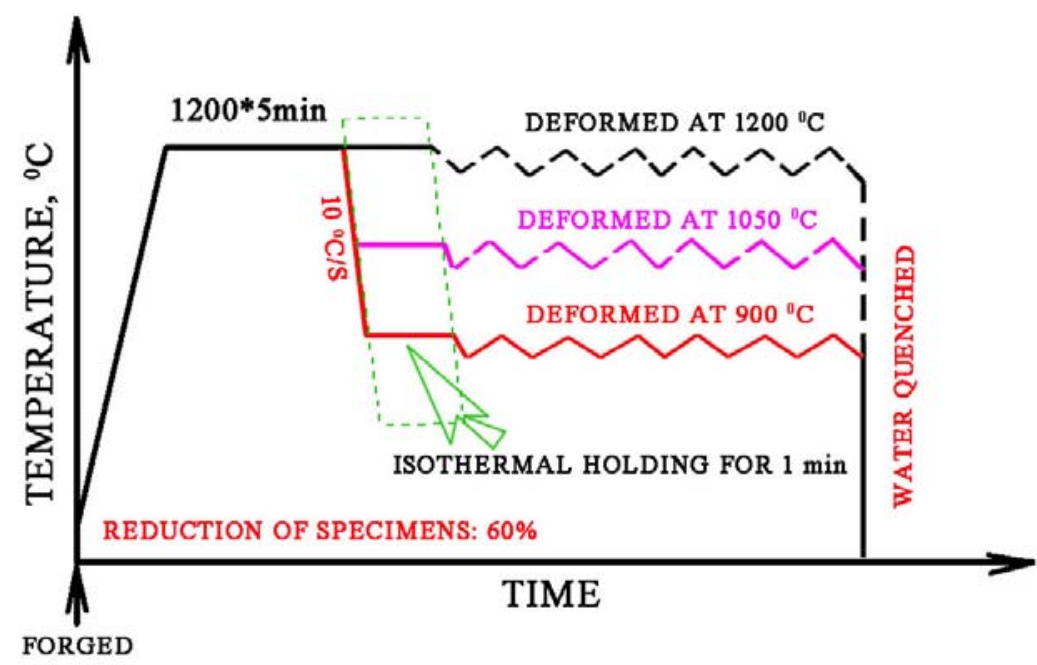

Fig. 1. The deformation procedure ${ }^{[9]}$. The sample was heated up to $1200{ }^{\circ} \mathrm{C}$ and cooled down to the deformation temperature of $900-1200{ }^{\circ} \mathrm{C}$ after being homogenized for $5 \mathrm{~min}$., then deformed at different strain rates of $10^{-3}-10 \mathrm{~s}^{-1}$ after the isothermal holding of $1 \mathrm{~min}$. Finally, the sample was quenched to room temperature as soon as the compression was finished.

The specimens were cut at approximately one third diameter position from the edge, shown in Fig. 2. The longitudinal section of the samples was polished and etched with Wheeler's reagent after grinding with 2000 mesh abrasive paper. The middle part of the longitudinal section was observed through a ZEISS MEF4A optical microscope and a HITACHI S3400N scanning electron microscope (SEM). The microstructure of deformed samples under different compression parameters was observed. 

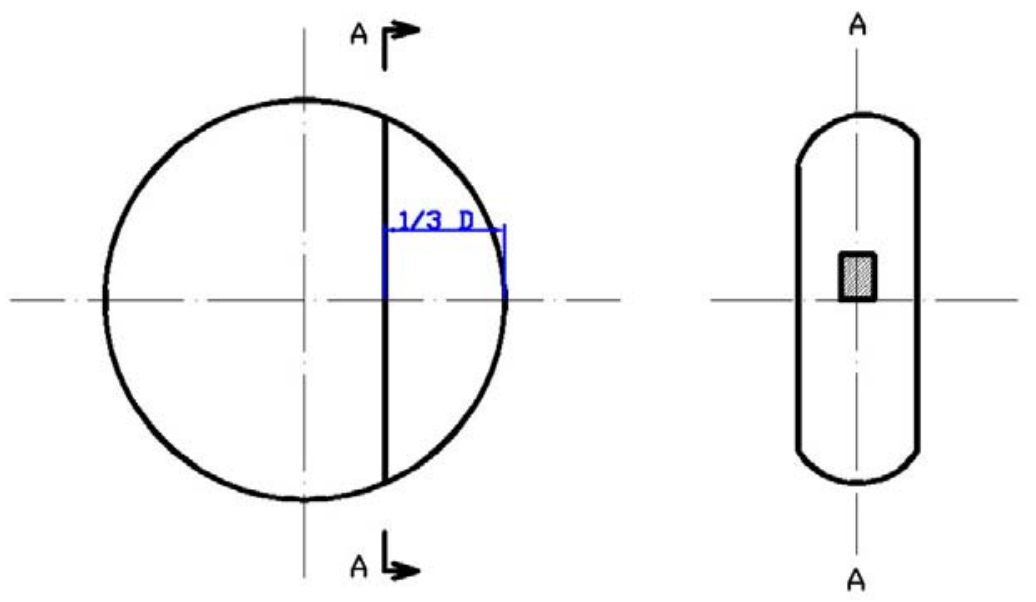

Fig. 2. Schematics of sectioning for metallographic specimens. The diagram on the right hand side shows the drum shape after large degree of deformation.

\section{Results and discussion}

\subsection{Stress-strain curves}

The stress-strain curves of the NS steel obtained from four different strain rates are shown in Figs. 3(a)-3(d). A separate set of figures, of these same data, was given in a previous publication ${ }^{[9]}$, to show the effect of strain-rate for each temperature. The critical strain, $\varepsilon_{c}$, and the peak strain, $\varepsilon_{p}$, which were determined through calculation of the deformation data using the method provided by previous researchers ${ }^{[6,10]}$, were marked on most of the curves. All the curves showed an initial work hardening but only a few out of them developed to a clear stress peak, such as the ones indicated with an arrow in Figs. 3(a) and 3(b). It was found that the distinct peaks, which indicate DRX taking place ${ }^{[5]}$, only appeared in the curves under high temperature and low strain rate deformation conditions (low $Z$ values). With the increase of $Z$ value in the beginning, taking stress curves in Fig. 3(a) for example, the peak became broad 
and the critical strain increased correspondingly. However, when $Z$ reached a higher level, such as the $900{ }^{\circ} \mathrm{C} / 1 \mathrm{~s}^{-1}$ deformation condition in Fig. 3(d), the stress curve showed a 'flat-top' shape with no obvious peak. This flat-top behavior of stress curve was traditionally thought to be an indication of no occurrence of DRX and implied that the dynamic recovery was the only softening mechanism operating during the deformation process $^{[7]}$.

It is also noticeable that the stress augmentation ratio, $\left(\sigma_{1 / \mathrm{s}}-\sigma_{0.001 / \mathrm{s}}\right) / \sigma_{0.001 / \mathrm{s}}$ calculated, in terms of the peak stress, decreased from about 2.56 to 0.97 with temperature decreasing from $1200{ }^{\circ} \mathrm{C}$ to $900{ }^{\circ} \mathrm{C}$. This diminishing influence of strain rate on flow stress as temperature is decreased is a reflection of the effective strain rate sensitivity $(m=\partial \log \sigma /(\partial \log \dot{\varepsilon}))$ of the material ${ }^{[9]}$. That the $m$ value was decreased with temperature declining and strain rate increasing was expected to be associated with the low stacking fault energy $(\mathrm{SFE})^{[7]}$. 

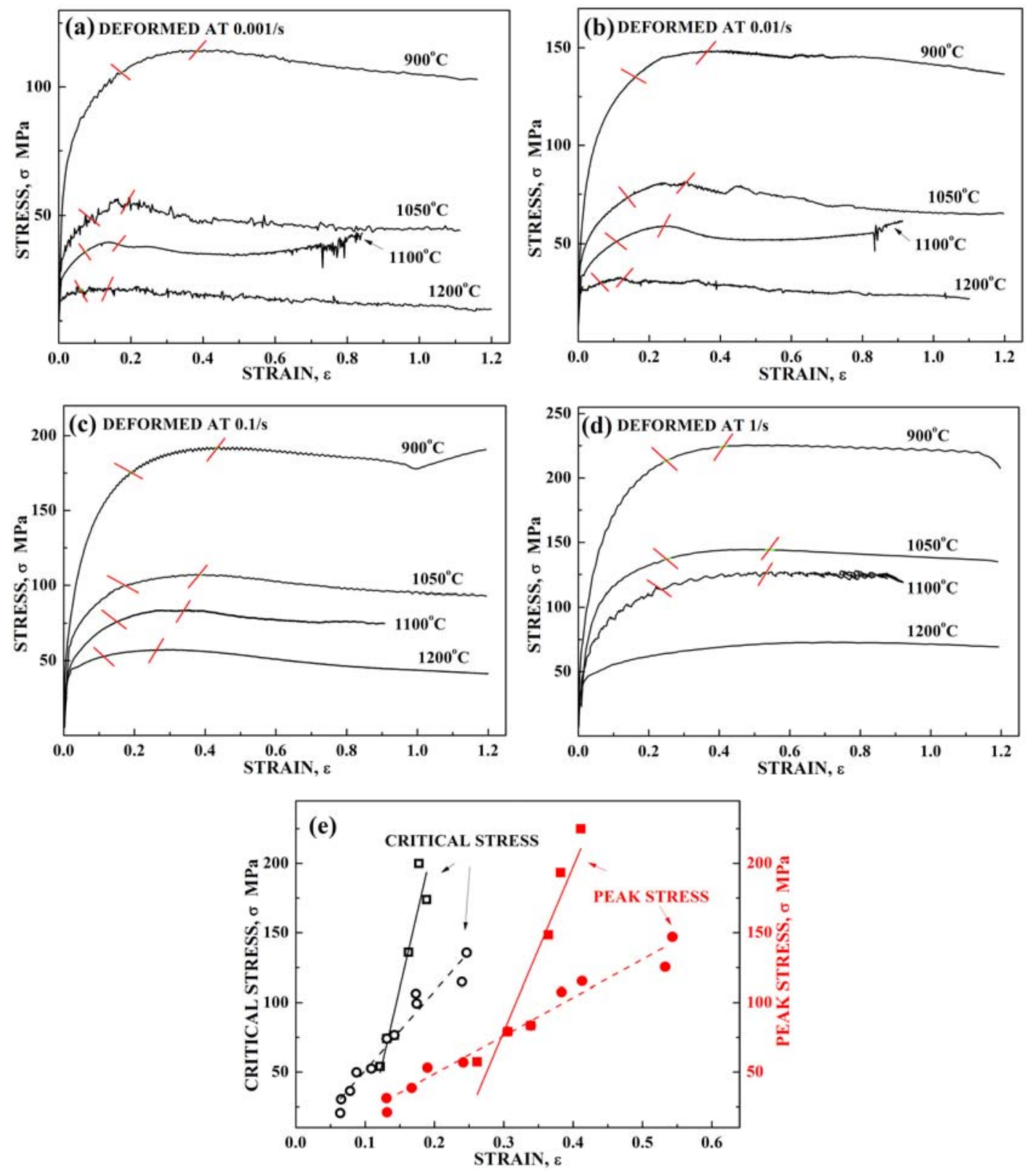

Fig. 3. The stress-strain curves with indication of $\varepsilon_{c}$ and $\varepsilon_{p}$ of the NS steel deformed at the strain rate of

(a) $0.001 / \mathrm{s}$, (b) $0.01 / \mathrm{s}$, (c) $0.1 / \mathrm{s}$, (d) $1 / \mathrm{s}$, and (e) the linear relationships between critical stress and critical strain showing two different slopes, and between peak stress and the peak strain showing two different slopes.

The critical stress rises linearly with the increase of critical strain for most of steels ${ }^{[5,10]}$, just like the peak stress with the peak strain. However, in the case of the 
NS steel, it was of interest that there existed two slope coefficients between the critical stress and the critical strain, as indicated in Fig. 3(e). As will be seen in Section 3.3, the major difference of microstructure at high $Z$ value and low $Z$ value was in the fraction of the ferrite in the microstructure. Meanwhile, in the previous work $^{[9]}$, it was explicitly explained that the growth rate of both DSIT ferrite grains and DRX grains was dramatically decreased at high $Z$ value, which made the MDRX the main mechanism in refining the microstructure. Therefore, the different slopes of critical stress and critical strain at high $Z$ value and low $Z$ value was assumed to be caused by the stress decrease that might be associated with the accelerated softening of DSIT. Based on the large volume of DSIT ferrite in the microstructure, DSIT occurred during the deformation and helped to reduce the dislocation accumulation significantly, and thus resulted in a lower stress at the same strain. Due to this effect, the DSIT process would enhance the workability and improve the ductility for the NS steel during hot deformation.

\subsection{Constitutive equations}

In analyzing the stress-strain curves, the reduced exponential function is generally used as shown in Eq. 1. In the equation, the flow stress $\sigma$ is expressed as a function of $\varepsilon$ as well as $T$ and $\dot{\varepsilon}^{[7]}$ :

$$
\sigma / \sigma_{p}=\left[\left(\varepsilon / \varepsilon_{p}\right) \exp \left(\varepsilon / \varepsilon_{p}\right)\right]^{C}
$$

where the exponent parameter $C$ can be derived. The peak strain $\varepsilon_{p}$ corresponds to the peak stress $\sigma_{p}$ employed in the constitutive equations. This formula is useful to determine the constitutive constants, such as peak stress and peak strain, through 
fitting the experimental stress curve to Eq. 1. The constitutive equations used for both high stress and low stress are defined as following ${ }^{[10]}$ :

$$
Z=\dot{\varepsilon} \exp (Q / R T)=A[\sinh (\alpha \sigma)]^{n}
$$

where $Z$ is the Zener-Hollomon parameter, $n$ is the stress exponent, $Q$ is the activation energy, $\alpha$ is constant for a fixed alloy, $R$ is gas constant which equals $8.314 \mathrm{~J} /(\mathrm{mol} \cdot \mathrm{K})$. All the parameters and the critical condition for each softening process happening before the peak can be calculated through Eq. 2 .

In order to use the data under different deformation conditions, it is necessary to obtain the constant coefficients in the constitutive equation first. The expansion of the hyperbolic function in a Taylor series is shown as below:

$$
\sinh (x)=\frac{e^{x}-e^{-x}}{2}=x+\frac{x^{3}}{3 !}+\frac{x^{5}}{5 !}+\frac{x^{7}}{7 !}+\ldots
$$

If $x \leq 0.5$, the higher order terms of $x$ can be ignored and the function is approximately equal to $x(\sinh (x) \approx x)$ with a relative error smaller than $4.0 \%$. Under that condition, the constitutive equation could be expressed as Eq. 4 . If $x \geq 2.0$, the term $e^{-x}$ can be ignored and the function is approximately simplified into $\sinh (x) \approx e^{x} / 2$ with a relative error smaller than $1.9 \%$. These simplifications change the constitutive equation into the following ${ }^{[7]}$ :

$$
\begin{array}{ll}
\dot{\varepsilon} \exp \left(Q_{H W} / R T\right)=A_{1} \sigma^{n} & \text { when } \alpha \sigma \leq 0.5 \\
\dot{\varepsilon} \exp \left(Q_{H W} / R T\right)=A_{2}[\exp (\alpha \sigma)]^{n} & \text { when } \alpha \sigma \geq 2.0
\end{array}
$$

where $Q_{H W}$ means the activation energy for the peak strain, $A_{1}=A \alpha^{n}$ and $A_{2}=A / 2^{n} . A_{1}$ and $A_{2}$ are material constants related to the values of $\alpha$ and $n$. After taking the logarithm of Eq. 4 and Eq. 5, the values of $n=\partial \ln \dot{\varepsilon} / \partial \ln \sigma_{p}$ and 
$\alpha=\partial \ln \dot{\varepsilon} /\left(n \cdot \partial \sigma_{p}\right)$ could be obtained from the slopes in $\ln (\dot{\varepsilon})$ vs. $\ln \left(\sigma_{p}\right)$ and $\ln (\dot{\varepsilon})$ vs. $\sigma_{p}$ curves, respectively. However, when judging whether the value of $\alpha \sigma$ is in the range of $\alpha \sigma \leq 0.5$ or $\alpha \sigma \geq 2.0$, it is necessary to know $\alpha$. An approximate value of $0.012 \mathrm{MPa}^{-1}$ was assumed to be a fixed value ${ }^{[8]}$. In the pre-evaluation of the NS steel, the peak stress values at the deformation temperature of $1200{ }^{\circ} \mathrm{C}$ and the strain rate of 0.001-0.05 $\mathrm{s}^{-1}$ were used in the condition of $\alpha \sigma \leq 0.5$ and the peak stress values at deformation temperature of $900{ }^{\circ} \mathrm{C}$ suit the condition of $\alpha \sigma \geq 2.0$. The original data for calculating the $\alpha$ value is listed in Table 2. From this initial calculation (Fig. 4), the $n$ and $\alpha$ values were determined to be 5.78 and $0.011 \mathrm{MPa}^{-1}$, respectively.

Table 2. Peak stress (MPa) data for calculating $\alpha$ value

\begin{tabular}{lll}
\hline Strain rate, $\mathrm{s}^{-1}$ & $900{ }^{\circ} \mathrm{C}$ & $1200{ }^{\circ} \mathrm{C}$ \\
\hline 0.001 & 115.3 & 21.0 \\
0.005 & - & 27.7 \\
0.01 & 148.5 & 31.2 \\
0.05 & - & 41.3 \\
0.1 & 193.4 & - \\
1 & 224.8 & - \\
\hline
\end{tabular}

In Table 2, some peak stress values are absent, because of the following. Data in Table 2 is used to calculate $\alpha$ and $n$ values through the slopes in $\ln (\dot{\varepsilon})$ vs. $\ln \left(\sigma_{p}\right)$ and $\ln (\dot{\varepsilon})$ vs. $\sigma_{p}$ curves. Initially, hot compression experiments were carried out only at $10^{-3}, 10^{-2}, 10^{-1}$, and $1 \mathrm{~s}^{-1}$ (Fig. 3), following the common choice of strain rates. 
These are the four data points for $900{ }^{\circ} \mathrm{C}$ tests, in Table 2 . However, in order to carry out regression for the condition of $\alpha \sigma \leq 0.5$, using the preferred four data points, additional data were necessary at $1200{ }^{\circ} \mathrm{C}$. Thus, two additional tests were carried out at $1200{ }^{\circ} \mathrm{C}$ at low strain rates, of 0.005 and $0.05 \mathrm{~s}^{-1}$, leading to the additional data points for these conditions in Table 2. Data are available for $1200{ }^{\circ} \mathrm{C}$ and strain rates of 0.1 and $1 \mathrm{~s}^{-1}$, but they are not needed for the regression calculation based on Eq. 4, because $1200{ }^{\circ} \mathrm{C}$ and strain rates of 0.1 and $1 \mathrm{~s}^{-1}$ do not satisfy the condition of $\alpha \sigma \leq 0.5$. In the case of $900^{\circ} \mathrm{C}$, four data points were already available for regression, so there was no need to conduct further experiments at 0.005 and $0.05 \mathrm{~s}^{-1}$, as more than four data points were not expected to change the regression results significantly.

The $Q$ and $A$ values could also be gained via the logarithmic form of the constitutive equation (Eq. 2), as shown in Eq. 6:

$$
\ln \left[\sinh \left(\alpha \sigma_{p}\right)\right]=\frac{1}{n} \ln (\dot{\varepsilon})-\frac{1}{n} \ln (A)+\frac{Q_{H W}}{n R T}
$$

Partially differentiating Eq. 6 yields ${ }^{[11]}$ :

$$
\begin{aligned}
& n=\frac{\partial \ln (\dot{\varepsilon})}{\partial \ln \left[\sinh \left(\alpha \sigma_{p}\right)\right]} \quad(\text { constant } T) \\
& Q_{H W}=n R \frac{\partial \ln \left[\sinh \left(\alpha \sigma_{p}\right)\right]}{\partial(1 / T)} \quad(\text { constant } \dot{\varepsilon})
\end{aligned}
$$

By putting $\alpha=0.011$ in the constitutive equation, the $n$ values under different deformation conditions were recalculated, using Eq. 7. The slopes of $\ln \dot{\varepsilon}$ vs. $\ln \left[\sinh \left(\alpha \sigma_{p}\right)\right]$ gave the $n$ value of $5.00 \pm 0.22$ for the NS steel as demonstrated in Fig.

5. Finally, the $\alpha$ value was adjusted to $0.012 \mathrm{MPa}^{-1}$ by recalculating with $n$ value of 5.00. After re-checking the value of $\alpha \sigma$ with $\alpha=0.012$ and $n=5.00$, the assumption of 
the ranges of $\alpha \sigma$ was proved to be correct. The activation energy $Q_{H W}$ of the experimental steel at the peak strain averaged from the slopes of the four regression lines shown in Fig. 5(b), for the four strain rates of tests, was $451 \pm 13 \mathrm{~kJ} / \mathrm{mol}$.

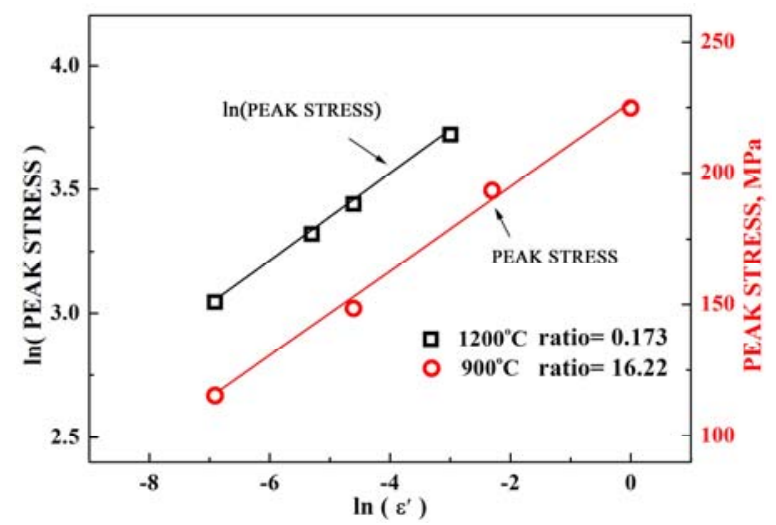

Fig. 4. Slope ratios of $\ln \left(\sigma_{p}\right)$ vs. $\ln (\dot{\varepsilon})$ and $\sigma_{p}$ vs. $\ln (\dot{\varepsilon})$ for calculating the values of constants $n$ and $\alpha$.
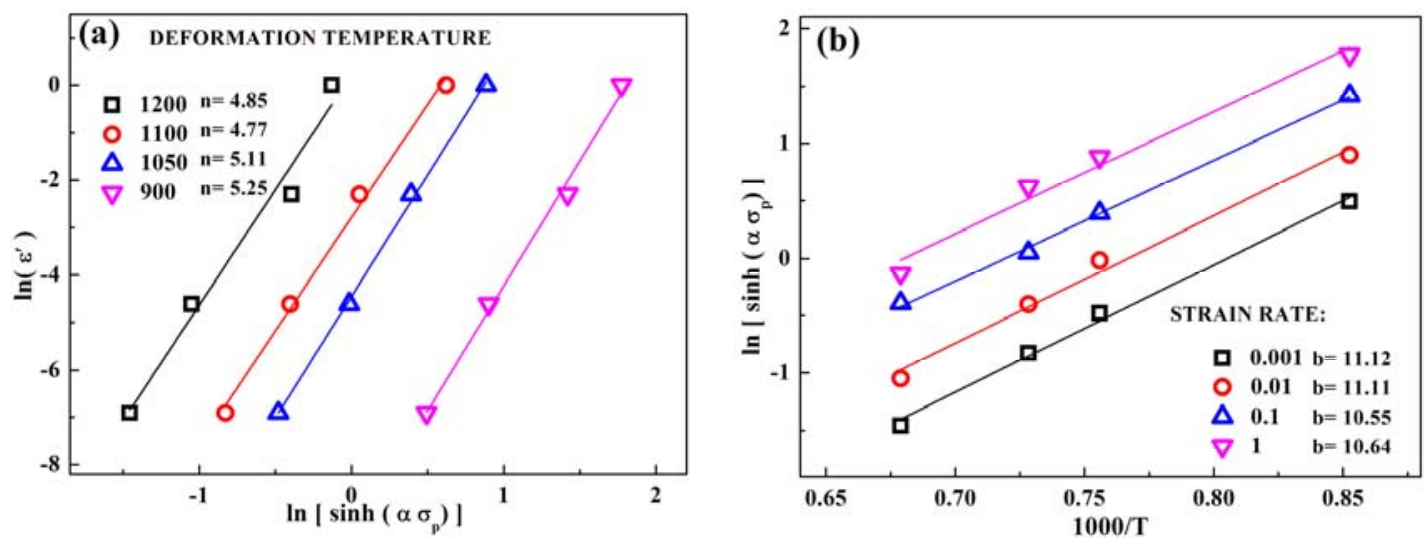

Fig. 5. Linear relationships (a) between $\ln (\dot{\varepsilon})$ and $\ln \left[\sinh \left(\alpha \sigma_{p}\right)\right]$ and (b) between $\ln \left[\sinh \left(\alpha \sigma_{p}\right)\right]$

and $10^{3} / T$ for the experimental steel.

\subsection{Microstructure evolution}

The evolution of microstructure during hot deformation was closely related to DRV,

DRX, MDRX and DSIT in the experimental steel. With the change of $Z$ value, the 
steel exhibited various microstructure characteristics, as demonstrated in Fig. 6(a). Fig. 6 is in small scales, to compare microstructure under different deformation conditions. This figure is not intended to show the detailed microstructure under each hot-working condition. The typical microstructures, for selected conditions, are presented in normal magnifications and further discussed in Section 3.4. From the change of microstructure displayed for different deformation temperature and strain rate, it was clear that different softening mechanisms took charge under different deformation conditions.

When the steel was compressed at low $Z$ value, the DRV which took place before DRX under all investigated conditions ${ }^{[10]}$ was encouraged. The DRX started at a lower strain and proceeded faster, because most of the metallic solutes that usually retard DRV and delay DRX were dissolved into the matrix ${ }^{[10]}$. The fine and medium size particles would effectively reduce the recovery process, but their numbers reduced. This reduction in number of fine and medium size particles would prompt the initiation of DRX, their effect on stabilizing the substructure by pinning the grain boundaries waning ${ }^{[8]}$. However, DSIT was retarded due to the increase of $\mathrm{Nb}, \mathrm{C}, \mathrm{V}$ and $\mathrm{N}$ contents in the matrix ${ }^{[7]}$, especially the $\mathrm{Nb}$ solutes which segregated at austenite boundaries and lowered the boundary energy, thus leading to a dramatic reduction in nucleation rate of DSIT ferrite ${ }^{[12]}$. In another respect, the deformation temperature was high enough for the nucleated DSIT ferrite to grow at a high speed. These above factors satisfied prerequisite to the occurrence of approximately equiaxed grains, 
taking the microstructure at the deformation temperature $1200{ }^{\circ} \mathrm{C}$ and the strain rate of $10^{-3} \mathrm{~s}^{-1}$ for example.

Decreasing the temperature (higher $Z$ ) ferrite nucleation would be promoted, but growth would be limited. So, with the $Z$ value increasing, the DSIT nucleation was prompted. This resulted in relatively finer ferrite grain size, according to some researchers ${ }^{[13,14]}$ who claimed that DSIT occurred at a critical strain by refinement of the prior austenite grain size in $\mathrm{C}-\mathrm{Mn}-\mathrm{V}$ steels. The $\mathrm{DRX}$ in austenite was dramatically delayed and the DRX in ferrite barely occurred due to the temperature decreasing and strain rate rising. Thus, with the $\ln (Z)$ value increase, DSIT ferrite formed and merged into allotriomorphic shape gradually and small amount of equiaxed martensitic grains formed. The typical change of microstructure was obtained under the deformation condition of $\ln (Z)$ value of 37-39.

The precipitates formed during deformation have a great influence on DRX, DRV and even DSIT and in turn effect the microstructure evolution. They played a very important role in microstructure evolution, but only through upsetting the process of DRX or accelerating the growth of DRX or DSIT grains. 


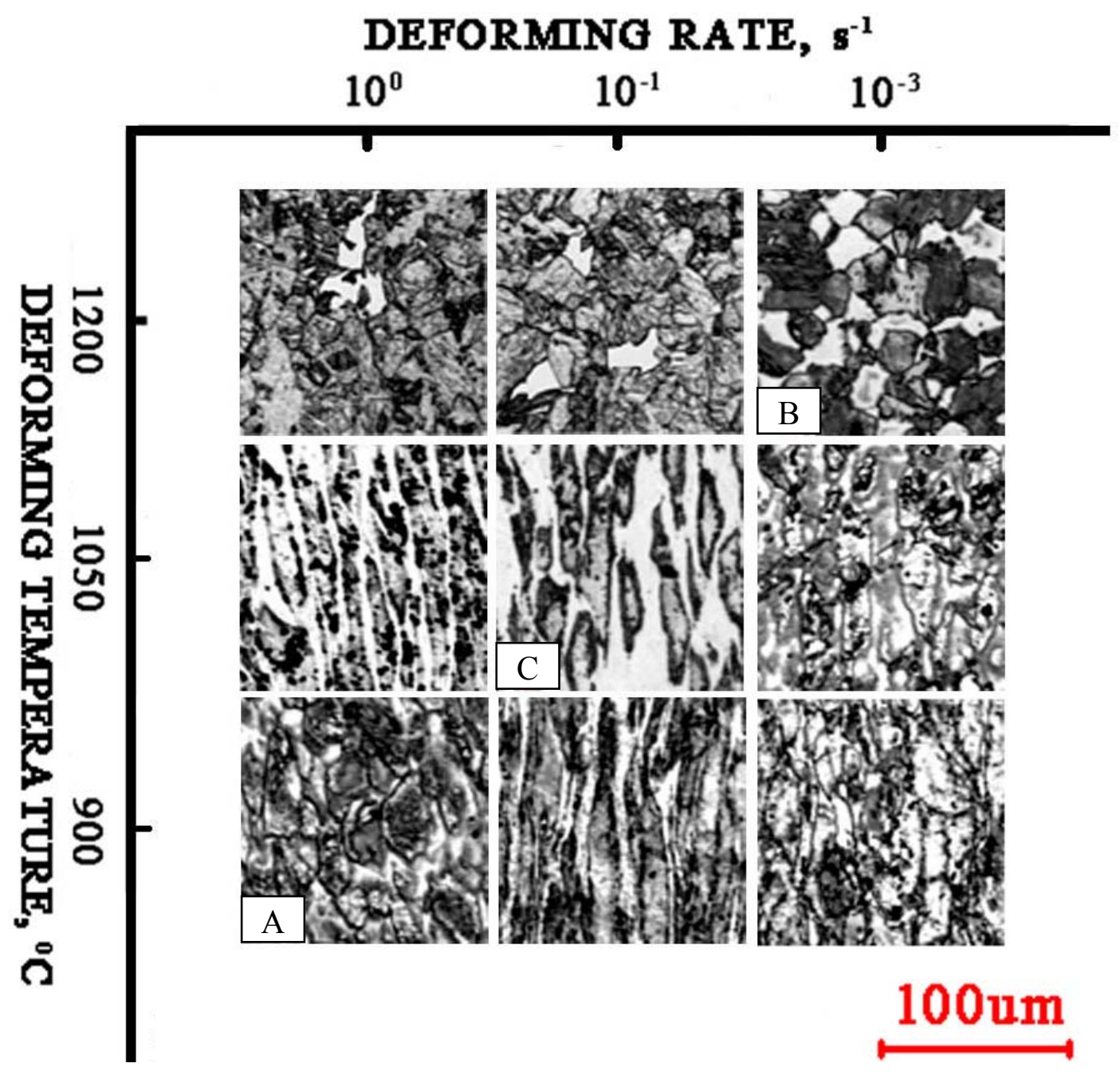

(a) 


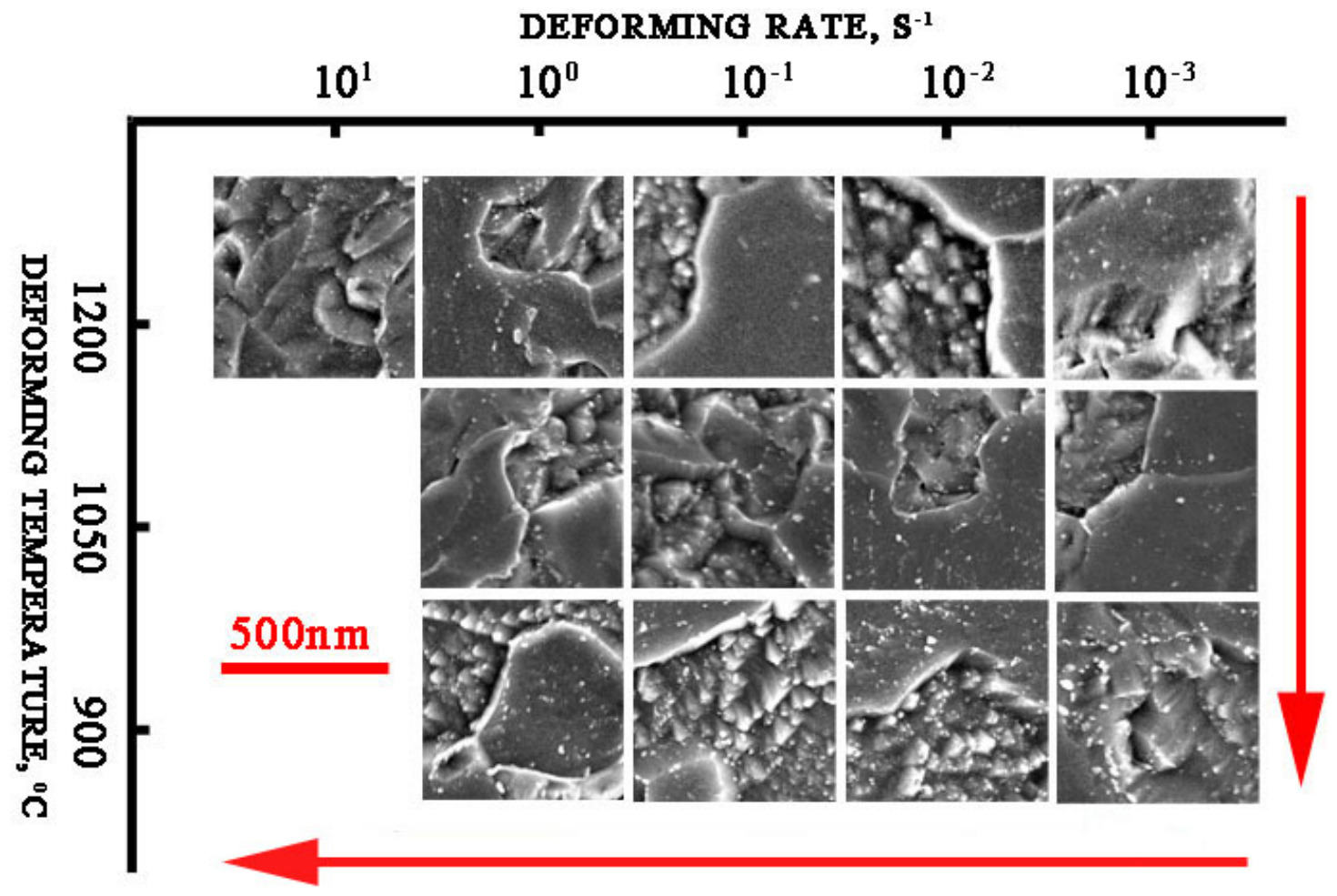

(b)

Fig. 6. Microstructure and precipitation evolution of the NS steel during hot deformation, deformed to the strain of 1.2. (a) Optical image of microstructure for different deformation temperature and strain rate; (b) SEM microstructure for different deformation temperature and strain rate.

As the $Z$ value continuously increased, especially when the deformation temperature was low (about $900{ }^{\circ} \mathrm{C}$, for instance), the growth of both DRX and DSIT grains almost stopped. The DSIT ferrite grains decreased to rarely exist owing to their extremely low growth, although the nucleation amount of DSIT barely changed due to the positive influence of strain induced precipitation ${ }^{[15]}$. The SEM observation in Fig. 6(b) gave a clear illustration that the amount of carbonitride precipitation increased gradually with the temperature decreasing and strain rate rising. This is why when the $\ln (Z)$ value increased to a certain level (around 66), there was rarely distinct DSIT ferrite left. Instead, the microstructure contained a certain volume of ferrite-martensite 
blend. Carbonitride precipitation also explains why the martensitic microstructure of high $Z$ value showed finer grains compared with that of low $Z$ value.

The particles tended to precipitate in the shape of sphere, as shown in Fig. 7(a). The diffraction patterns of the precipitates and the matrix are given in Fig. 7(b), indexed. The diffraction spots indexed by circles form the diffraction pattern of the precipitates. However, since the number of precipitates was low and the size of them was small, only a few diffraction spots were observed. According to the chemical composition of the experimental steel and the high deformation temperature (above $900{ }^{\circ} \mathrm{C}$ ), the spherical shape precipitates were assumed to be niobium carbonitrides of the MX type.
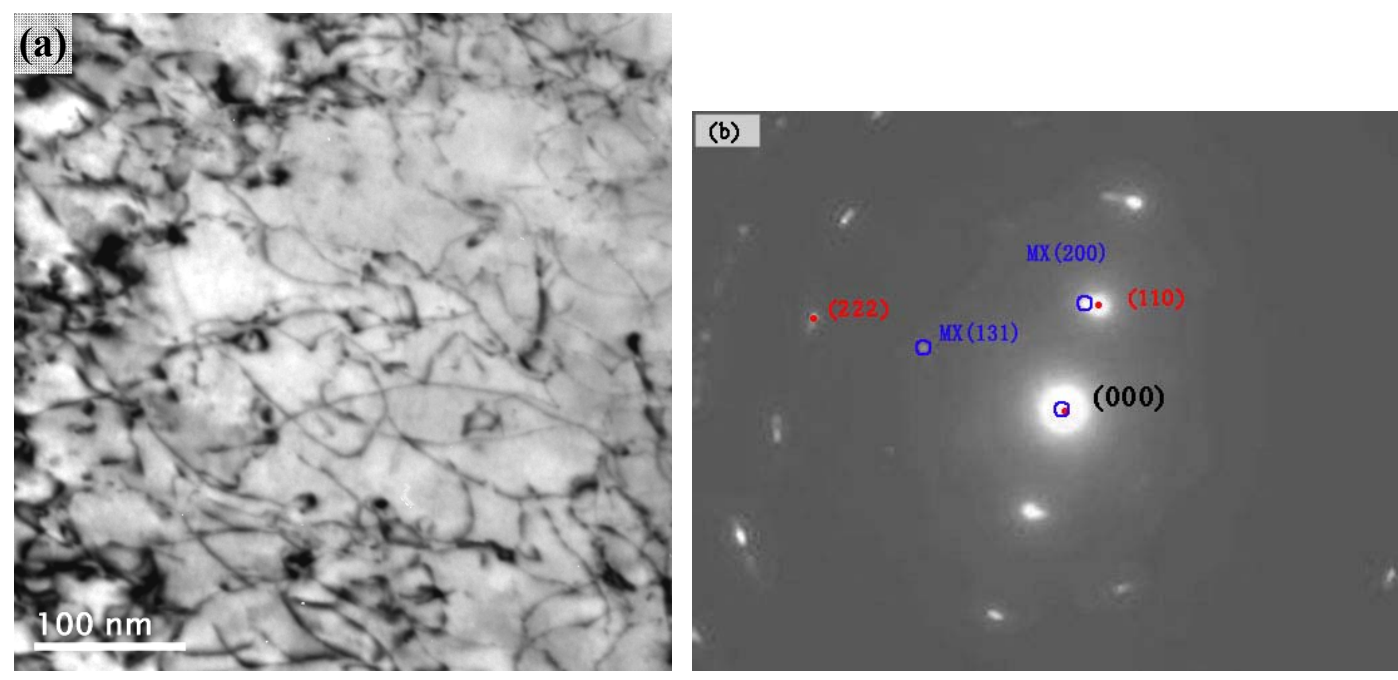

Fig. 7. The precipitates formed during deformation. (a) TEM image of precipitates; (b) the diffraction patterns of the precipitates shown by circles and the martensitic matrix shown by dots.

\subsection{Processing maps at a strain of 0.6}

The processing map is very effective to describe deformation behavior in the term of power dissipation ratio $\eta$, which determines the extent of power dissipation due to 
the changes of microstructure during the deformation. The parameter $\eta$ was expressed as the following ${ }^{[16]}$ when $m$ is independent of the strain rate:

$$
\eta=\frac{J}{J_{\max }}=\frac{m \sigma \dot{\varepsilon} /(m+1)}{\sigma \dot{\varepsilon} / 2}=\frac{2 m}{m+1}
$$

where $m$ denotes the strain rate sensitivity. $J$ implied the power dissipated by microstructure changes, while most part of the energy disappeared through heat release and plastic deformation during the deformation. As common understanding, $\eta$ varies with the deformation temperature and strain rate.

It is generally expected that the maximum value of $\eta$ implies the optimum hot working condition for the deformation. However, high value of $\eta$ may also result from wedge cracking which is a kind of flow instability. In order to elicit the instability condition during hot deformation, Eq. 10 was proposed by Ziegler $^{[17]}$ :

$$
\xi(\dot{\varepsilon})=\frac{\partial \ln [m /(m+1)]}{\partial \ln (\dot{\varepsilon})}+m>0
$$




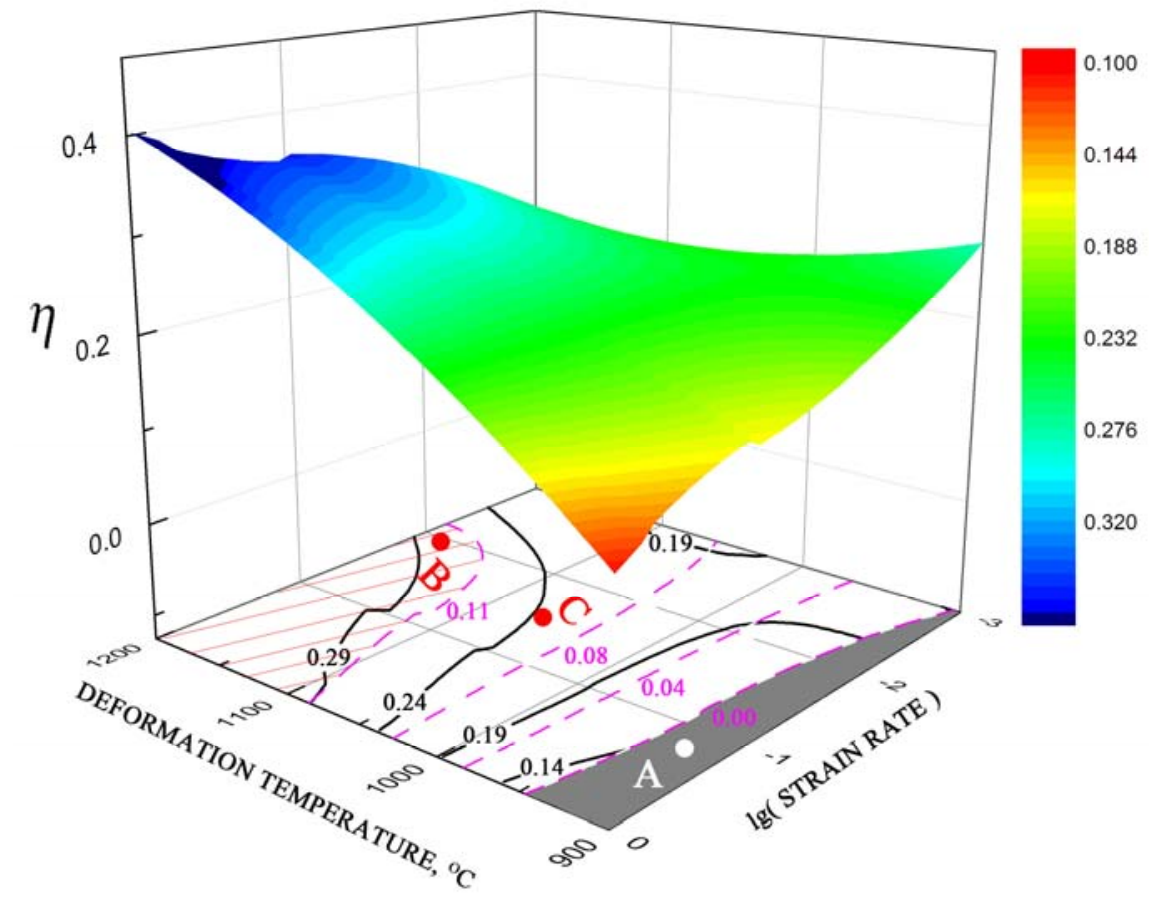

Fig. 8. Three-dimensional processing map of the NS steel at the strain of 0.6. The broken contour lines on the bottom plane give the $\xi(\dot{\varepsilon})$ value, while the solid contour lines on the bottom plane give $\eta$ value. The colour scale to the right hand side of the figure shows $\eta$ value, too. A, B and C are typical spots in the three regions. 

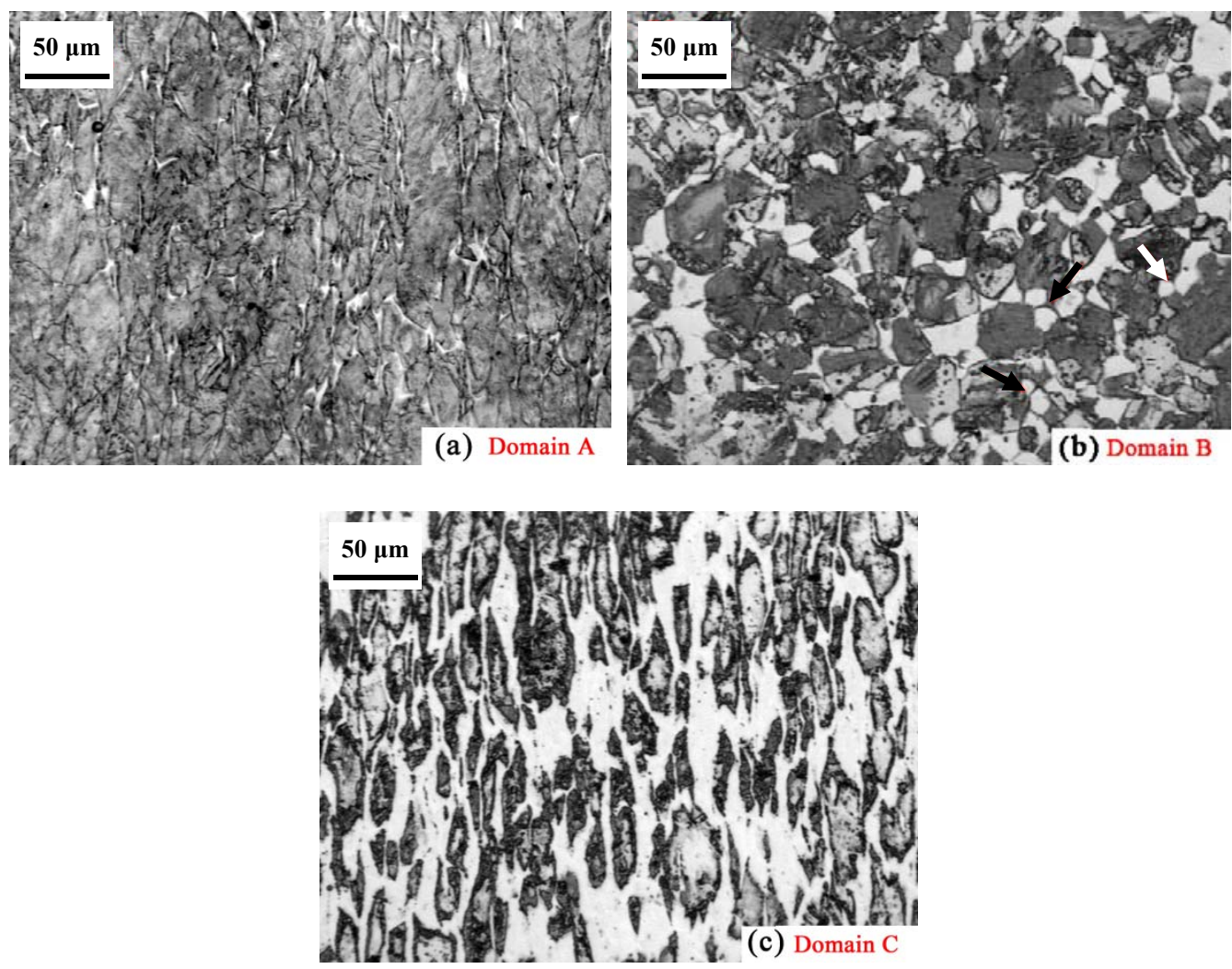

Fig. 9. Optical image of microstructure being associated with different regions in the processing map,

(a) domain A, (b) domain B, and (c) domain C. Data was from the strain of 0.6 , so the microstructure was slightly different from Fig. 6(a).

The variation of $\xi(\dot{\varepsilon})$ with temperature and strain rate yielded an instability map in which the instability regions were characterized by negative values of $\xi(\dot{\varepsilon})$. Fig. 8 illustrates a three dimensional power dissipating map for the NS steel at the strain of 0.6 along with the dissipation contours and the instability shadow region at the bottom projection.

The instability map of the NS steel had three typical regions marked as A, B and C in Fig. 8. The distribution of three typical regions was somehow associated with the efficiency of power dissipation. For instance, region A (the instability domain), where $\xi(\dot{\varepsilon})$ was negative (see the broken contour lines on the bottom plane of Fig. 8, giving 
the $\xi(\dot{\varepsilon})$ value), had a small value of $\eta$, around 0.1 . Region $\mathrm{B}$, in which the NS steel had an excellent plasticity, mainly lay in the high $\eta$ area.

Domain B was related to the excellent plasticity with a high $\eta$ value. From the observation of microstructure in Fig. 9(b) and the discussion of microstructure evolution above, it was obvious that when deformation happened under this condition, both DRX and DSIT occurred in the microstructure evolution. Even some of the DSIT ferrite might also experience DRX under this condition according to the microstructure observation, arrow indicated in Fig. 9(b). Therefore, the rapid processes of DRX and DSIT used the stored energy very quickly and sustained superplastic deformation. However, there was no distinct evidence to prove that DRX happened in DSIT ferrite in the $\mathrm{C}$ region. Instead, the DSIT ferrite in the $\mathrm{C}$ region displayed a stripe shape with wide width along the prior austenite boundaries, shown in Fig. 9(c). In this region, according to the analysis of microstructure evolution, the growth of DSIT ferrite along with the DSIT process used much of the energy stored during the compression. Thus, these two softening mechanisms together kept the $\eta$ value at a relatively high level and consequently better workability in this region than in the A region. When the NS steel was deformed at region A, it was expected to have poor workability and low $\eta$ value since the microstructure was comprised of elongated grains and DSIT ferrite with small width along the prior austenite grain boundaries, shown in Fig. 9(a). This feature of the microstructure was assumed to be caused by no noticeable DRX occurring during the hot deformation ${ }^{[18]}$ and slow growth of DSIT ferrite. Otherwise, the grains would be equiaxed and the DSIT ferrite with a wide 
width. Thereby, in this case, only the DSIT process, not the growth of DSIT ferrite or the DRX, would play a significant role in avoiding the nucleation and propagation of wedge crack.

The efficiency of power dissipation maps along with instability maps of the experimental steel in the strain range of $0.05-0.60$ is presented in Fig. 10. The NS steel barely had any instability region (shadow area) above the temperature of $1000{ }^{\circ} \mathrm{C}$ and beyond the strain of 0.2 . Each of the instability area at different strains was small owing to the lower $\mathrm{C}$ and $\mathrm{N}$ contents comparing to the commercial $\mathrm{P} 92$ steel. Both DRX and DRV were encouraged due to the reduction of the pinning effect of carbonitrides precipitated during the hot deformation. From the distribution of the shadow areas, it could be concluded that the optimum processing condition for the NS steel was $1000-1200{ }^{\circ} \mathrm{C} / 0.001-1 \mathrm{~s}^{-1}$ beyond the strain of 0.2 .

(See separate graphics file)

Fig. 10. The instability maps, illustrated by the dashed contour lines, and processing maps, illustrated by the solid contour lines at a strain range of $0.05-0.6$ for the NS steel.

\section{Conclusion}

Beneath the diversity of microstructures and hot deformation processes, there are some fundamental characteristics of the martensitic heat resistant steel as follows.

(1) There exhibited two different slopes in the linear relationships between $\sigma_{c}$ and $\varepsilon_{c}$ for the NS steel in the stress-strain curves. 
(2) Through analysis of the flow curves of the NS steel at different deformation temperatures and strain rates, the $\alpha$ parameter was calculated to be $0.012 \mathrm{MPa}^{-1}$.

(3) The processing map could be identified into three domains corresponding to three different levels of workability, namely excellent workability region with very high $\eta$ value being associated with approximately equiaxed grains, good workability region with high $\eta$ value related to stripe-shape grains, and the poor workability region with low $\eta$ value and elongated grains.

\section{Acknowledgements}

This work was financially supported by National Basic Research Program of China (No. 2010CB630800) and National Natural Science Foundation of China (No. $51001102)$.

\section{References}

[1] I. von Hagen, W. Bendick, "Creep resistant ferritic steels for power plants." In Proceedings of the International Symposium on Niobium, 2001, pp. 753-776.

[2] W.F. Zhang, P. Hu, Q.G. Zhou, W. Yan, Y.Y. Shan, K. Yang, Effect of heat treatment on the mechanical properties and the carbide characteristics of a high strength low alloy steel, J. Iron Steel Res. Int. supplement 1-1, 18 (2011) 143-147.

[3] Å. Gustafson, M. Hättestrand, Coarsening of precipitates in an advanced creep resistant $9 \%$ chromium steel—quantitative microscopy and simulations, Mater. Sci. Eng. A 333 (2002) 279-286.

[4] W.F. Zhang, W. Yan, W. Sha, W. Wang, Q.G. Zhou, Y.Y. Shan, K. Yang, The impact toughness of a nitride-strengthened martensitic heat resistant steel, Sci. China Technol. Sci. 55 (2012) 1858-1862.

[5] A.S. Taylor, P.D. Hodgson, Dynamic behaviour of 304 stainless steel during high $Z$ deformation, Mater. Sci. Eng. A 528 (2011) 3310-3320.

[6] E.I. Poliakt, J.J. Jonas, A one-parmenter approach to determining the critical conditions for the initiation of dynamic recrystallization, Acta Mater. 44 (1996) 127-136.

[7] H.J. McQueen, S. Yue, N.D. Ryan, E. Fry, Hot working characteristics of steels in austenitic state, J. Mater. Process. Technol. 53 (1995) 293-310. 
[8] A.I. Fernández, P. Uranga, B. López, J. Rodriguez-Ibabe, Dynamic recrystallization behavior covering a wide austenite grain size range in $\mathrm{Nb}$ and $\mathrm{Nb}-\mathrm{Ti}$ microalloyed steels, Mater. Sci. Eng. A 361 (2003) 367-376.

[9] W.F. Zhang, X.L. Li, W. Sha, W. Yan, W. Wang, Y.-Y. Shan, K. Yang, Hot deformation characteristics of a nitride strengthened martensitic heat resistant steel, Mater. Sci. Eng. A 590 (2014) 199-208.

[10] H.J. McQueen, N.D. Ryan, Constitutive analysis in hot working, Mater. Sci. Eng. A 322 (2002) 43-63.

[11] A. Marchattiwar, A. Sarkar, J.K. Chakravartty, B.P. Kashyap, Dynamic Recrystallization during Hot Deformation of 304 Austenitic Stainless Steel, J. Mater. Eng. Perform. 22 (2013) 2168-2175.

[12] S.C. Hong, S.H. Lim, H.S. Hong, K.J. Lee, D.H. Shin, K.S. Lee, Effects of Nb on strain induced ferrite transformation in C-Mn steel, Mater. Sci. Eng. A 355 (2003) 241-248.

[13] H. Beladi, G.L. Kelly, A. Shokouhi, P.D. Hodgson, The evolution of ultrafine ferrite formation through dynamic strain-induced transformation, Mater. Sci. Eng. A 371 (2004) 343-352.

[14] H. Dong, X.J. Sun, Deformation induced ferrite transformation in low carbon steels, Curr. Opin. Solid St. M. 9 (2005) 269-276.

[15] M. Militzer, W.P. Sun, J.J. Jonas, Modelling the effect of deformation-induced vacancies on segregation and precipitation, Acta Metall. Mater. 42 (1994) 133-141.

[16] A. Momeni, K. Dehghani, Hot working behavior of 2205 austenite-ferrite duplex stainless steel characterized by constitutive equations and processing maps, Mater. Sci. Eng. A 528 (2011) 1448-1454.

[17] H. Ziegler, Progress in Solid Mechanics, Wiley, New York, 1965, pp. 191-193.

[18] W. Zhang, Y. Liu, H.Z. Li, Z. Li, H.J. Wang, B. Liu, Constitutive modeling and processing map for elevated temperature flow behaviors of a powder metallurgy titanium aluminide alloy, J. Mater. Process. Technol. 209 (2009) 5363-5370. 


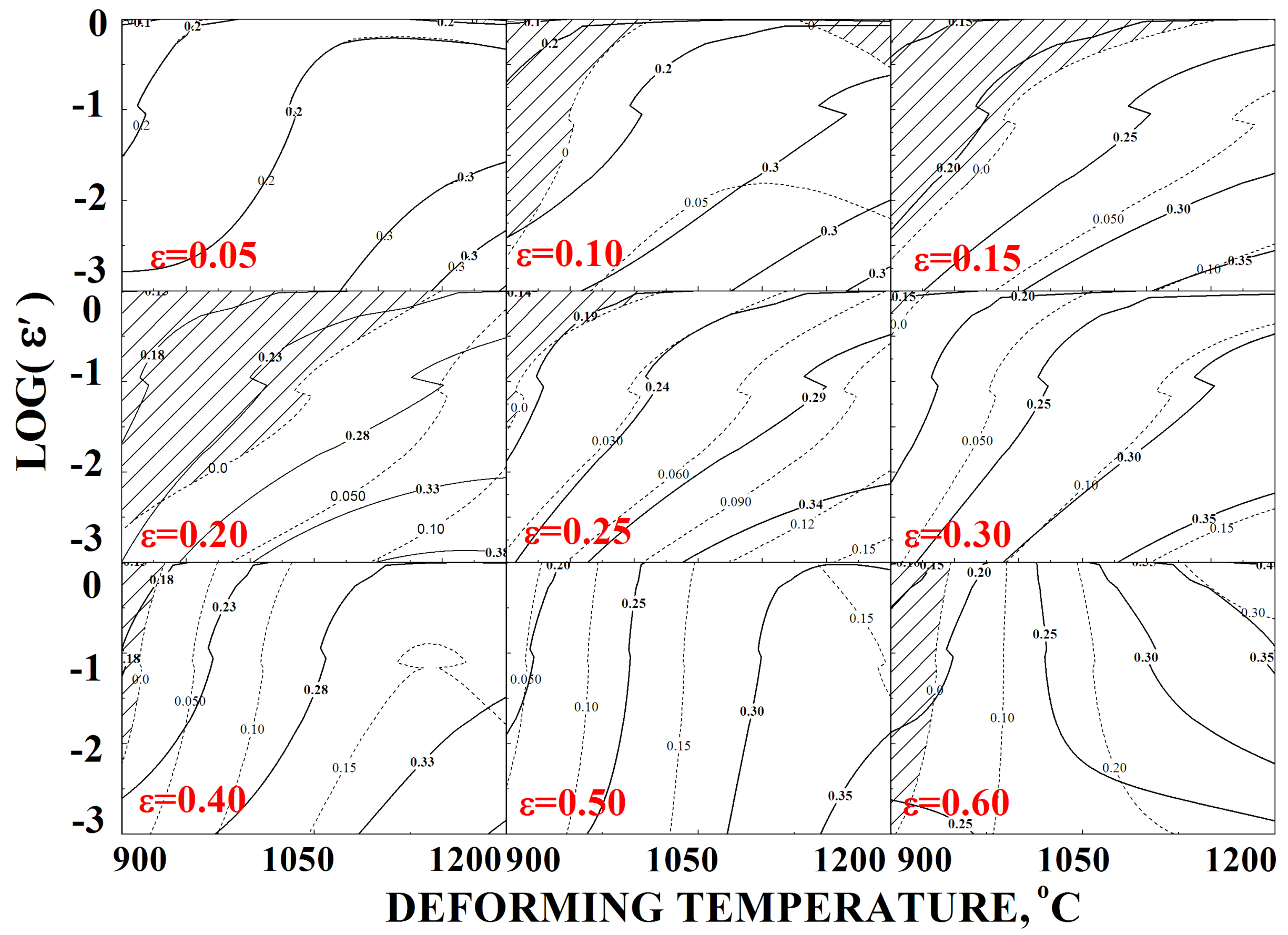

